
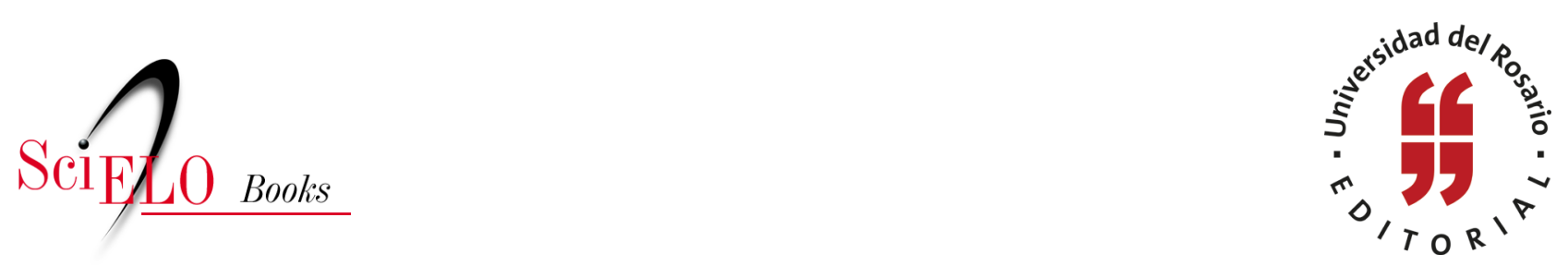

\title{
16. Cuando uno se va a manejar mal, no hay quién lo ataje
}

\author{
César Augusto Tapias Hernández
}

\section{SciELO Books / SciELO Livros / SciELO Libros}

TAPIAS HERNÁNDEZ, C.A. Cuando uno se va a manejar mal, no hay quién lo ataje. In: Historias de familia: Etnografía delirante sobre el amor, la violencia y las drogas [online]. Bogotá: Editorial Universidad del Rosario, 2014, pp. 67-71. Textos de ciencias humanas collection. ISBN: 978-958-738543-4. https://doi.org/10.7476/9789587385434.0017.

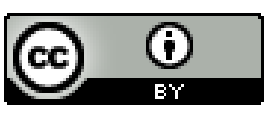

All the contents of this work, except where otherwise noted, is licensed under a Creative Commons Attribution 4.0 International license.

Todo o conteúdo deste trabalho, exceto quando houver ressalva, é publicado sob a licença Creative Commons Atribição 4.0.

Todo el contenido de esta obra, excepto donde se indique lo contrario, está bajo licencia de la licencia $\underline{\text { Creative }}$ Commons Reconocimento 4.0 . 


\title{
16. Cuando uno se va a manejar mal, no hay quién lo ataje
}

\author{
Benedicto: ¿cuál es la ofensa, dulce Beatriz? \\ Beatriz: me habéis detenido en un feliz momento, estaba a \\ punto de protestar que os amo. \\ William Shakespeare, Mucho ruido y pocas nueces
}

Mi tía Melia y su novio Alejandro siempre conversaron, pues él y mi papá fueron compañeros de colegio. Se dejaban por tiempos, entonces ella conseguía otros novios, y él también conseguía otras novias... Pero Alejo siempre la mantuvo como arrocito en bajo, siempre molestando, “y eso que era muy perro; pero ¡nos casamos!”. A él lo querían mucho en la casa de los abuelos. Fonso decía que era muy verraco, porque el día que pidió la arrimada a la casa para visitar a Rome, fue y sudaba que daba miedo, y lo hizo... Pero la tía interrumpe su relato y me dice:

- ¿Por qué me preguntas eso?

- ¿Le choca o qué tía? - contesto.

Con sus palabras entrecortadas, aguadas por lágrimas... Melia se pone triste y yo espero a que se tranquilice. Le acerco un poco de agua... Espero... Y recuerdo mientras tanto... a Alejo al volante de su camión, un HI:

-Un día Alejandro volvió en su camión, y me dijo "listo, negra, yo sé que esa es la única forma....”.

Cuando él la iba a visitar aprovechaban las salidas de Melia a la "dentistería" para averiguar dónde los casaban. Terminaron en la Iglesia del Perpetuo Socorro. Hasta el último momento mintieron:

-Que es que vivíamos juntos y nos queríamos mucho... Y yo la verdad sé que él me quería más a mí, que yo a él; pero yo se lo había dicho: que yo no quería a nadie, fue entonces cuando le puse mi condición. 
Hicieron el cursillo, consiguieron las argollas. En fin... la fecha señalada fue el 4 de agosto. Él insistía que quería verla de un vestido bien lindo.

— ¿Cómo?, ahí sí me pillaban —dijo Melia.

Ocho días antes ella había sido madrina de una niña que bautizaron por allá abajo en "El Baratón”, y había estrenado un vestido apenas para la ocasión.

—Ese día solo me lo puse un momentico, entonces decidí casarme con él. La mentira ya estaba montada: me creyeron otra vez el cuento de la dentistería y que luego visitaría a una amiga... Pero resulta que Álvaro, un primo de Alejandro, no pudo llegar con mi partida de bautismo, que era del municipio de Heliconia. No pudimos casarnos ese día. Mi amá casi nos pilla: que qué era esa llamadera de Alejandro y bueno... con el cura se había arreglado nuevamente una misa para el día siguiente a las 12 . Yo le dije a Alejo que ya le tocaba a él organizarlo todo, que yo ya no podía con otra mentira. Él la planeó y fue y le dijo a mí apá: “que como él al otro día salía temprano para Barranquilla y que solo a las 12 le iban a pagar un cheque, que si me dejaba salir a reclamarlo y mi apá no puso problema.... Me demoré lo que duró la misa. Yo cogí ahí mismo pa' mi casa, apenas si hubo tiempo pa' una gaseosa. Los padrinos fueron Martha Inés, la amiga a la que supuestamente iría a visitar, y el doctor Sanín, amigo de Alejo. Él mismo nos prestó un carrito cuando después de casados volvimos a la ciudad.

-Y entonces ¿cómo quedaron las cosas?, ¿se casaron, y?

-Por la noche Alejandro apareció con una borrachera, que me cogía a picos y yo que no: "Alejo, mira, que nos van a pillar". Y mi apá le pregunta que qué hubo del viaje: "no, don Fonso, vea la hora que me entregaron el camión", dijo el conchudo.

Alejo volvió unas cuatro veces más, normalmente, como cualquier visita de novios y no hubo nada, ni cuando estaba él en la cama por unos hongos que le dieron en los pies: yo lo visitaba y le compraba la droga; pero él en la cama yo en una silla... Y mi mamá que le metió una vaciada a la tía de él, allá donde él se quedaba a amanecer... Quién sabe qué se imaginaba

En una de esas veces, le trajo un vestido desde la ciudad de Barranquilla y unas chanclas. La mamita Gélica llamó a Fonso, y Melia escuchó lo que se decía:

-Que ahí estábamos, pero que todo era normal. Yo me estaba poniendo troza...

— ¿Estabas en embarazo o qué tía?

— ¡No te digo que nada de nada, pues! Y mi amá dándonos vueltas como con ganas de preguntar quién sabe qué. Incluso dejé solo a Alejandro a ver si ella arri- 
maba y preguntaba algo y nada vos. Al otro día, mi apá me sale con la cantaleta de que cuidado como hacía las cosas... Ese día era definitivo, el definitivo...

Alejandro decía que ya no se aguantaba sin Melia. Se vistió y cuando mi papito Fonso la vio con el vestido y las chanclas explotó: "Que si estaba en embarazo, que si me iba a casar o qué había hecho que últimamente estaba muy rara”.

-Yo le dije: "Sabe qué, apá... Me casé con Alejandro". Y le expliqué por qué lo había hecho... Huy, es que todavía me acuerdo y me da tanta rabia. Mi amá decía que él era poco hombre y los muchachos llorando, Raúl, Hétor Mario, Willi... Yo esperaba a Alejo desde las cuatro. Esa era la quinta vez que nos veíamos después del matrimonio y cuando él llegó le conté que mis papás ya sabían. Alejo se metió una macheta atrás por si mi apá le tiraba; pero cuando entró, él le preguntó que qué era lo que habíamos hecho y Alejo le decía “tranquilo, don Fonso, siéntese y hablamos”, y mi amá rebotada. Y los muchachos sentados. Mi apá les dijo que se acercaran.

— “Déjalo hablar..., le decía su papito a mi amá... Entonces ella se fue para las escalas reclamándole el que no me hubiera dado ni siquiera un vestido... que disque las argollas fueron un par de latas ahí... decía ella.

-Mijo, usted ya es como de la familia, decía mi apá y mi amá encima...

-Quédese, insistía mi apá, ¿pa' donde se la va a llevar?

-No, don Fonso, doña Gélica no quiere, yo me llevo a la negra en mi camión.

Y Alejo le da por decirle a mi amá que me diera la bendición...

-Que se las dé el que los casó — decía ella.

—Negra, recoja sus cosas — puntualizó Alejo. Hasta matas me llevé. Y los muchachos llorando.

En el barrio Villa Hermosa nos guardaron las cosas y yo me iba con Alejandro a viajar, pagábamos hotel. Como a los dos meses llamé a su papá. Él y yo siempre nos la llevamos muy bien, nos vinimos a pelear fue en estos días. Bueno... él me dijo: "Loca, ¿dónde estás...? Pasen por acá por el bombeo donde estoy trabajando".

Por esos días, mi papá era operador de aguas en municipios como Abejorral y Guarne... Cuando se vieron, le pidió a Melia que viera al papito Fonso, que él estaba muy mal, sufriendo del corazón.

-Uno y otro después de verme le dijeron a mi amá que yo no estaba en embarazo, aunque para todos por aquí, sí. Aún hay quienes creen que Juan Camilo nació antes de casarme, pero él nació a los dos años de casados.

-Yo me acuerdo del apartamentico en El Pedregal que ustedes tenían por ahí donde estaban viviendo antes de venirse para acá.

- Sí, ahí nació Juan Camilo. 
Esta es la historia del matrimonio de mi tía Melia con Alejo. Al final, pienso que luego de tanto tiempo Alejandro sigue fiel a lo que implica una aventura, como casarse al escondido, como viajar sin tener asegurado pa'l regreso. Ahora que soy un adulto y tengo pase de conducción, me encantaría volver a manejar su camión... Desde este balcón, el mejor lugar de la casa de mis abuelos, allí donde me cogí estos detalles y otros que me reservo por puro respeto a mi tía y a mi mamita Gélica, me parece estar viendo el HI, a mis primos y al tío Ed correteando en el planchón. Hace 23 años se casó la tía, desde eso y quizás más, Alejo tiene ese camión, Paula ya tiene 15 años y mi primo Juan Camilo... quien hizo de patrullero de la Policía, en el teatro de la guerra, muere luego bajo un bombardeo de las FARC-EP al hotel donde dormía.

$\infty \infty \infty$

Ver cada pequeño gran drama de la familia consanguínea nos permite hacer referencia a todas las formas posibles de familia. Desde la extensa, concebida como pilar del ethos tradicional, hasta la díada madre-hijo(a), a la cual se le ha concedido legitimidad. Así lo propone Linton (1965, p. 158), citado por Hernán Henao:

Todas las sociedades reconocen la existencia de ciertas unidades cooperativas compactas, organizadas internamente, intermedias entre el individuo y la sociedad a la que pertenece. Teóricamente, toda persona pertenece a una $u$ otra de estas unidades, por razón de relaciones biológicas establecidas por el ayuntamiento sexual o la ascendencia común. De hecho, tal asignación puede también apoyarse sobre la base de sustitutos reconocidos, como la paternidad supuesta y la adopción. Estas unidades tienen siempre funciones específicas en relación tanto con sus miembros como con el total de la sociedad. (1995, p. 2)

En los estudios de Virginia Gutiérrez de Pineda (1975) encontramos que la característica básica de este complejo agrupamiento social es la forma de unión, la cual es de facto o de unión libre, y la integración familiar, cuya etiología se encuentra en la continua movilidad de los hombres que desde jóvenes van de un lugar a otro en busca de mejores condiciones de vida, o actividades remuneradas, resulta bastante débil. Lo que podemos ver, además, es que hay una serie de funciones en la familia que vienen de su doble condición biológica y cultural, como son la reproducción, la producción económica, el cuidado de los ancianos, la protección de sus 
miembros contra los extraños y la educación y cuidado de los hijos. Es la condición de socialización o endoculturación que Onfray (2008) propone a la familia, en tanto es el lugar del vínculo entre la instancia doble del individuo (en) la sociedad.

Y aquí, aparece el punto en torno al que el profesor Hernán Henao propone sus interrogantes apropósito de Medellín y la crisis que vive esta ciudad (y la familia) desde los años setenta, a lomo de caballo entre los valores tradicionales de la sociedad rural decimonónica y los nuevos valores que propone la urbe, y es que en la instancia de la socialización se suponen conscientes o, por lo menos, presentes las actividades propias de la trasmisión de patrones de comportamiento entre hombres y mujeres, y grupos humanos de todo orden y condición:

Las reflexiones sobre Medellín vienen de todos lados, por la crisis que ha vivido su población en los últimos años del $\mathrm{S}$ Xx, se ha llegado al punto de afirmar que la ciudad esta sobrediagnosticada, y ahora lo que se ha debido hacer es adelantar acciones que permitan superar las situaciones de tensión social, conflicto, delincuencia, narcotráfico, terrorismo, en que se han visto envueltos todos los pobladores del Valle de Aburrá. (Henao, 1995, p. 3)

En contextos como este, las uniones son el resultado de transitorias atracciones físicas. Pasadas estas temporadas, o las tensiones y conflictos que reseña Hernán Henao, las mujeres vuelven a quedar solas y las uniones se deshacen; sin embargo, la desintegración hogareña no limita a las mujeres en sus tareas biológicas. 